\title{
PROTAGONISMO DOS ÍNDIOS NORTE-AMERICANOS NOS DESENHOS ANIMADOS DE WALTER LANTZ
}

\author{
RAFAEL DUARTE OLIVEIRA VENANCIO ${ }^{1}$ \\ CENTRO UNIVERSITÁRIO SENAC - SP
}

\begin{abstract}
RESUMO: Condenados a uma duvidosa representação midiática no início do cinema graças aos romances do final do século XIX, os índios norte-americanos nunca tiveram um grande destaque nos filmes dessa época. No entanto, um realizador de desenhos animados, Walter Lantz, possui um alto grau de caracterização de nativos norte-americanos em seus trabalhos. $O$ objetivo do presente artigo é estudar o protagonismo dos índios norte-americanos nesses desenhos animados, e analisar as implicações sociais dessas escolhas através do uso dos conceitos de dispositivo e fórmula. Além disso, a análise incluirá a retratação da cena midiática norte-americana antes e depois de Lantz, buscando rupturas e legados.
\end{abstract}

PALAVRAS-CHAVE: Walter Lantz; Cultura indígena; cinema de animação; linguagem fílmica.

ABSTRACT: Condemned to a dubious media representation in early cinema through the novels of the late nineteenth century, the North American Indians never had a high profile in films of this period. However, an animator, Walter Lantz, has a high degree of characterization of Native Americans in his work. The aim of this paper is to study the role of Native Americans in these cartoons and analyze the social implications of these choices, using the concepts of apparatus and formula. Furthermore, the analysis will include a portrayal of the American media scene before and after Lantz, seeking disruptions and legacies.

KEYWORDS: Walter Lantz; Indian culture; Animated cinema; film language.

Desde seu início, em sua fase silenciosa, o cinema não retratou com muita consideração os povos nativos da América do Norte. Sendo chamados de índios ou pelo nome de alguma tribo com algum passado histórico notório com os colonizadores europeus, as personagens indígenas norte-americanas não tinham um tratamento narrativo

\footnotetext{
${ }^{1}$ Professor da graduação em Tecnologia em Produção Audiovisual do Centro Universitário Senac (São Paulo) e Doutorando em Meios e Processos Audiovisuais da Escola de Comunicações e Artes da Universidade de São Paulo. E-mail: rdovenancio@gmail.com .
}

Espaço Ameríndio, Porto Alegre, v. 5, n. 1, p. 102-128, jan./jun. 2011. 
RAFAEL DUARTE OLIVEIRA VENANCIO - Protagonismo dos índios norte-americanos...

individualizado - ou seja, sem nome ou mesmo sem distinção individual na trama -, e tinham uma função muito clara na história: serem uma massa de vilões.

Muito mais do que vilões, os índios norte-americanos eram identificados como seres desleais, capazes de atitudes antiéticas e desumanas que nenhum vilão "branco" poderia realizar. Nas histórias, eles eram os vilões por natureza, sem motivo para atacar os pioneiros do Velho Oeste.

Normalmente a literatura dos Estudos do Cinema considera que o tratamento mais simpático - dando o protagonismo fílmico - aos nativos acontece nos anos 1990, mas com controvérsias, no surgimento de filmes tais como Dances With Wolves (1990), The Last of the Mohicans (1992) e Geronimo (1993).

No entanto, há um fato normalmente esquecido pelos pesquisadores do campo audiovisual. Já nos anos 1940, quando os westerns de John Ford e John Wayne eram líderes de audiência, encontramos um tratamento protagonístico e simpático dos índios norte-americanos nos desenhos animados feitos por Walter Lantz, o criador de Woody Woodpecker, o Pica-Pau.

$O$ presente artigo quer analisar qual foi a forma de tratamento narrativo dedicado aos índios norte-americanos nesses desenhos animados, e qual seria a função social dessa representação ficcional desse grupo étnico. Para isso, utilizaremos, além da análise do corpus dos desenhos do Pica-Pau e sua turma, feitos por Walter Lantz, os conceitos de fórmula e de dispositivo.

Antes disso, vamos fazer uma revisão fílmica do tratamento da personagem indígena norte-americana no cinema desde os princípios até os anos 1940. Tudo isso para que, ao acionar todo esse arcabouço teórico, possamos ver os pontos de ligação e de influência que o trabalho de Lantz causará na cena audiovisual posterior a ele.

\section{Western e os Injuns: o estigma do vilão na raiz do preconceito}

A produção de westerns no cinema se mistura com o próprio início da prática. Muito mais do que coincidência, esse dado remete ao 
fato de que o nascente gênero literário do western, que inicia sua força em 1850, estava em seu auge no começo do século XX, atraindo os estúdios a realizarem adaptações desses textos para a grande tela.

No entanto, seja nos textos (normalmente a ficção western era vendida em revistas de baixo custo conhecidas como dime novels) ou nos filmes, os índios norte-americanos já possuíam um papel bem definido: o de vilões.

Só que o tipo de vilão dedicado aos indígenas não era o mesmo daquele retratado nos bandidos de ascendência europeia. Enquanto estes podiam ter algum passado doloroso ou mesmo o sentimento da ganância, os índios norte-americanos eram retratados enquanto maus por natureza, preparando ardis em casos de uma vingança torpe.

Além disso, na grande maioria das vezes, não era dedicada uma individualidade aos indígenas. Tratados enquanto massa, o máximo que recebiam era serem chamados de "Índio", ou outras palavras depreciativas, mas socialmente aceitas entre os exploradores do Velho Oeste, tais como Injun.

Duas fontes célebres podem ser referenciadas enquanto bons exemplos do pensamento corrente da sociedade norte-americana branca acerca dos indígenas. O primeiro são as ideias de George Washington, bem representativas do que a esfera política pensaria por, pelo menos, dois séculos.

Envoltos na guerra de expansão territorial do nascente Estados Unidos, os militares norte-americanos retratavam aos seus superiores um cena bárbara, onde os índios jamais se renderiam, e cometeriam as atrocidades que fossem para tirar o último branco de suas terras.

Washington, já eleito o primeiro presidente do país, e Henry Knox, seu secretário de Guerra, acreditavam que a guerra era necessária para a consolidação da cidadania do novo país. Aliás, a guerra entre os índios que não aceitavam o convívio com brancos em suas terras era vista como um mal necessário.

Mal necessário esse que tinha raiz não em uma maldade natural do índio, mas sim por um defeito da sociedade indígena. Washington e Knox acreditavam que as atitudes extremas que os índios faziam na usualmente chamada Northwestern War (MILLER, 1994) eram meras consequências do fato de não serem civilizados e viverem em uma 
sociedade cuja estrutura social e de poder beneficiava tais atitudes.

Assim, essa "guerra civilizatória" teria o papel de promover seis itens, buscando uma integração dos indígenas no guarda-chuva pátrio dos Estados Unidos: (1) tratamento imparcial de justiça (quem cometeu crimes deve ser punido tal como qualquer cidadão norte-americano); (2) compra regulada das terras indígenas; (3) promoção do comércio; (4) promoção de experimentos para civilizar ou evoluir a sociedade indígena; (5) autorização de presentes presidenciais para estabelecer relações de paz; e (6) punir qualquer um que violasse os direitos indígenas.

Esses seis itens foram declamados por Washington em seu Terceiro Discurso Anual para o Congresso, em 25 de outubro de 1791 e, de certa forma, tinham mais o caráter de um discurso legitimador do processo civilizatório do que a representação de medidas de facto.

Assim, desde a fundação dos Estados Unidos da América até, principalmente, a Corrida para o Oeste, o processo civilizatório dava as duas opções aos índios: integrar-se à grande nação americana ou morrer na defesa de uma sociedade considerada por esses colonizadores como imperfeita, bárbara e, até mesmo, maligna.

No entanto, até mesmo os indígenas integrados à sociedade do branco norte-americano eram alvo do preconceito demonstrado pela caracterização do nativo enquanto tendo as características inatas de maldade e vingança. Um bom exemplo disso é a obra de Mark Twain de 1876, The Adventures of Tom Sawyer2.

Um dos principais antagonistas desse livro de ficção de amplo sucesso em sua época é Injun Joe, um indígena mestiço. Mas, tal como Twain deixa claro, o seu sangue nativo, com sua maldade inata, é o que Ihepermite criar os piores ardis.

Ora, Injun Joe é o personagem máximo do público preconceito de Mark Twain em relação aos índios norte-americanos. Tal como Adriana Rissetto (1996) aponta, boa parte da produção literária de Twain acerca dos índios não só servia para exprimir seu preconceito racial, mas também para criticar a caracterização romântica dos indígenas por James Fenimore Cooper, cinquenta anos antes de seu tempo.

Cooper, apesar das diversas críticas acerca de sua falta de

\footnotetext{
${ }^{2}$ Cf. Twain (2011).
} 
referencialidade, é considerado um proeminente caracterizador positivo dos nativos norte-americanos. Curiosamente, seu principal livro sobre o assunto, The Last of the Mohicans (1826) ${ }^{3}$, nunca teve uma adaptação fiel no cinema: ou foi feita sob o olhar do preconceito (1920 e 1936) ou, mesmo quando foi uma exaltação indígena, foi feito enquanto veículo de uma história água com açúcar que tirou todas as descrições positivas da sociedade indígena (1992). Mas, sem dúvida, os onze livros de Cooper sobre os nativos norte-americanos eram as poucas produções literárias, na época, onde poderiam ser encontrados índios protagonistas e caracterizados enquanto sábios, heroicos ou justos.

Twain discordava claramente disso, usando o nome de Cooper em seus textos. Heroísmo, sabedoria e justiça jamais poderiam ser obtidas, em sua visão, nesses seres naturalmente maus. Um dos primeiros textos de Twain, The Noble Red Man (1870)4, tem o objetivo de mostrar que o índio alto, musculoso, direito e nobre de Cooper é, "na realidade", pequeno, atarracado, obscuro e sujo.

Esse é Injun Joe, grande vilão de The Adventures of Tom Sawyer. Motivado por uma vingança injusta - já que tinha sido punido justamente no contexto da narrativa -, Injun, cuja palavra em si já é preconceituosa queria realizar as piores maldades e torturas com a esposa de quem o puniu, o Sr. Douglas, já falecido.

A vida e o fim de Injun Joe são metáforas da visão preconceituosa de Twain. Punido por ser um mendigo, maldoso por natureza, e preso em uma caverna até a morte - onde a única coisa que restou dele foi sua tigela, que logo virou um ponto de turismo -, Joe indica que o sangue indígena, para Twain, só tem espaço enquanto pária social ou memória turística.

Enquanto que as críticas a Cooper e o preconceito de Mark Twain eram gradualmente desacreditados nos círculos literários e acadêmicos, o sucesso da caracterização negativa dos indígenas por Twain continuou a ganhar terreno fértil na cultura popular. Os traços de Injun Joe ecoavam em qualquer vilão indígena do começo do século $X X$, principalmente naqueles presentes no nascente cinema, cuja fórmula necessitava de mocinhos e antagonistas bem definidos.

\footnotetext{
${ }^{3}$ Cf. Cooper (1982).

${ }^{4}$ Cf. Twain (1996).
} 
RAFAEL DUARTE OLIVEIRA VENANCIO - Protagonismo dos índios norte-americanos...

À essa situação de realização fílmica que se deve, em parte, a má interpretação dos primeiros filmes de The Last of the Mohicans, fugindo da intenção inicial de Cooper. Assim, nesses filmes (1920 e 1936), há a perda do destaque ao núcleo indígena heroico (Chingachgook, Uncas) para o crescimento dos heróis brancos (Natty Bumppo e os Munro) e do vilão indígena (Magua e a tribo dos Huron).

A extensa quantidade da produção de filmes western no começo do século XX impede uma caracterização precisa da quantidade de filmes em que os indígenas são retratados. Além disso, a maioria dos filmes é considerada perdida, principalmente aqueles dos pequenos estúdios.

No entanto, é sabido que nenhum índio era ator naqueles tempos. Tal como o blackface, havia um extenso redface, atores brancos que se pintavam para parecerem índios nos filmes. Tal como no caso dos negros, esse tipo de interpretação dos atores já tinha em si um preconceito racial e uma depreciação a priori do papel do indígena na sociedade norte-americana.

Tradicionalmente, John Ford é considerado o primeiro cineasta a retratar os indígenas com mais respeito. Seu filme Stagecoach (1939), um marco e reviravolta no gênero fílmico do western, é considerado inovador por um tratamento diferenciado aos indígenas, tanto diegeticamente - o filme é quase um nascimento do anti-herói, com a figura de Geronimo, o chefe dos Apaches, e, também, da expressão "eu estava torcendo para os índios vencer" - como em termos de casting, ao colocar indígenas para interpretar indígenas, sendo Geronimo interpretado pelo Chief White Horse.

A grande inovação de Stagecoach é que John Ford, na verdade, não colocou espaços para heróis, só anti-heróis. Assim, tanto os membros da diligência (uma prostituta, um alcoólatra, um vendedor de uísque, um fugitivo da justiça) como os Apaches têm seus lados positivos e negativos, não só possibilitando o espectador se identificar com o lado que bem quiser (não há mocinho e bandido), mas também colocando o indígena norte-americano não enquanto alvo de matança e genocídio, mas sim enquanto um lado legitimado.

No entanto, não podemos considerar que John Ford promoveu a fórmula do anti-heroísmo ao extremo, onde todas as personagens 
RAFAEL DUARTE OLIVEIRA VENANCIO - Protagonismo dos índios norte-americanos...

tivessem esse mesmo tratamento equânime (afinal, em Stagecoach, ainda é mais fácil torcer por John Wayne do que pelos índios). No cinema western, isso só seria atingido pelo chamado Spaghetti Western, quando cineastas europeus resolvem fazer produções $B$ do gênero, só que desprendidos do tradicionalismo norte-americano.

Só que, no mesmo período histórico de Stagecoach, havia nos Estados Unidos alguém que construía um universo de anti-heróis. Só que não era nos gêneros do cinema tradicional, mas sim nos curtas de desenho animado. Esse era o campo do trabalho de Walter Lantz.

\section{O outro cotidiano das personagens de Walter Lantz}

Em uma atividade dominada por Walt Disney, no auge do seu bom mocismo com fábulas, tais como a Branca de Neve, e personagens bem comportadas, tais como o Mickey, Walter Lantz era uma espécie de ampla reação da prática midiática do desenho animado contra isso.

É bom notar que o bom mocismo de Disney não era à toa. Para manter o seu estúdio produtivo nos anos 1930 , ele não só tinha que agradar aos seus financiadores conservadores - em uma época logo de recessão, logo após a Quebra da Bolsa de Nova lorque, em 1929 -, mas também atender às normas de autocensura do Código Hays, divulgadas em 1930 e implementadas em 1934.

A autocensura da indústria cinematográfica surge por causa de um processo ideológico iniciado na década anterior. No começo dos anos 1920, o cinema era considerado uma arte de baixa moral, e relatos de filmes assim - do mainstream ou não - invadiam as páginas do jornal.

Com o sucesso crescente dos filmes e desenhos animados, setores conservadores da sociedade civil começaram a colocar pressão financeira e política em cima dos grandes estúdios e distribuidores. Escândalos de ordem sexual, tal como aquele que envolveu o ator cômico Fatty Arbuckle, em 1921, fizeram esses setores acreditarem no cinema enquanto promotor de subversão.

Com medo de perder seus negócios ou de ter intervenção governamental, a indústria cinematográfica resolveu se autocensurar. 
RAFAEL DUARTE OLIVEIRA VENANCIO - Protagonismo dos índios norte-americanos...

Em 1922, todos os principais estúdios e distribuidores se reuniram para formar a Motion Picture Producers and Distributors of America (MPPDA, que, após a Segunda Guerra Mundial, virou MPAA ou Motion Picture Association of America).

Para presidi-la, os chefões dos estúdios tiraram um membro do alto escalão do governo Warren Harding, o chefe dos correios, Will $\mathrm{H}$. Hays. Conservador, republicano e diácono presbiteriano, Hays era a figura certa para melhorar a imagem da indústria diante da sociedade civil.

Após muitas conversas, Hays anunciou, em 1930, a criação de um código de autocensura, a ser posto em prática em 1934. Boa parte das gags da época - que focavam drogas, sexismo, insinuações sexuais e, até mesmo, violência e a temática da morte - estavam proibidas.

Famoso por desenhos mais anárquicos junto com seu parceiro e sócio Ub Iwerks, Walt Disney aproveitou a saída de seu amigo, em 1930, para deixar mais a realização de seus desenhos animados apenas na mão de seus comandados. A última palavra tinha que ser dele ou de Roy e, tal como qualquer outra empresa, criar linhas-guia para as produções, inclusive para Mickey que, afinal, levava a voz de Walt.

Assim, surge o bom mocismo, que se torna a marca registrada de Disney, identificada enquanto a melhor forma de atender as determinações do Código Hays. No entanto, Lantz, sem precisar se arriscar a perder dinheiro e sem desobedecer às leis de autocensura, conseguiu fugir de ser cópia de Disney.

Nascido em 1899, Lantz resolveu se transformar em realizador de desenhos animados ao assistir Gertie the Dinosaur, de Winsor McCay. Após ser estagiário no estúdio de John R. Bray, vai para a Califórnia, onde trabalha, principalmente, em agências de publicidade.

Em 1928, por causa das leis vigentes e da falta de patente, o distribuidor Charles Mintz retira a personagem Oswald the Lucky Rabbit de Disney e Iwerks, e contrata Lantz para ser o diretor da série de curtas do coelho. No entanto, com o advento do Mickey, o interesse por Oswald diminuiu e a Universal resolveu, por um acordo, tirar Oswald de Mintz e produzi-lo autonomamente.

Lantz continuaria sendo o diretor e, ao vencer o presidente da Universal, Carl Laemmle, em um jogo de pôquer, ganhou os direitos 
RAFAEL DUARTE OLIVEIRA VENANCIO - Protagonismo dos índios norte-americanos...

sobre Oswald. Agindo nas lacunas do Código Hays, Lantz conseguiu manter a diegese anárquica do coelho sortudo, tal como concebida por Ub Iwerks, e ter um relativo sucesso.

Tornando-se um estúdio independente em 1935, Lantz começou a testar novas personagens, mas sem encontrar nenhum grande sucesso. Reza a lenda, contestada por Maltin (1987, p. 168), que, em 1940, na lua de mel com sua segunda esposa, a atriz Grace Stafford, Walter Lantz teve a ideia de criar Woody Woodpecker, baseado em um pica-pau que estava perturbando o sono dos recém-casados.

É sabido que, ao montar seu estúdio próprio, Walter Lantz tinha como alvo rivalizar com Disney. Para isso, ele tentou copiar a estrutura de negócio do seu rival para aproveitar todas as boas lições obtidas por Walt.

Primeiro foi a obtenção das patentes de todos os personagens tal como feito com Oswald no jogo de pôquer. Depois, Lantz queria fazer desenhos animados musicais - tal como nas produções Disney, o metrônomo era um instrumento essencial e visto nas mesas dos animadores, tal como fotos de época comprovam -, mas o seu orçamento (e o da Universal, que distribuía seus curtas) não permitia pagar os direitos de um extenso leque de opções.

Depois, foi a vez de Lantz tentar realizar um desenho animado de longa metragem, praticamente uma exclusividade da Disney desde Snow White and the Seven Dwarfs, sobre a história de Aladdin. No entanto, os custos de produção eram proibitivos demais.

A solução foi montar uma turma de personagens, tal aquela inaugurada por Disney ao criar amigos protagonistas de Mickey, tais como Pluto, Pateta e o Pato Donald. Lantz acreditava que o seu Mickey seria Andy Panda. Criado em 1939, Andy entrava na nova regra de Lantz: só criar personagens pouco tradicionais.

Assim, Woody Woodpecker, sendo um animal pouco tradicional, seria ideal para a turma de Andy Panda. Sua função seria clara: a de fazer a mesma "função" de Donald - a de atrapalhar -, tal como bem mostra o seu primeiro curta, Knock Knock, de 1940. No entanto, o sucesso do coadjuvante superou o do protagonista e Woody se tornou o chefe da turma.

Turma essa que, diferente daquela da Disney, só era composta 
RAFAEL DUARTE OLIVEIRA VENANCIO - Protagonismo dos índios norte-americanos...

por personagens nada tradicionais no desenho animado. Além de um pica-pau e de um urso panda, Lantz criou uma gama de personagens baseados em animais pouco usuais, tais como um urubu, um jacaré, um pinguim, uma morsa, entre outros.

No entanto, como a turma era do politicamente incorreto e maníaco Woody Woodpecker - e não mais do amável (porém ganancioso) Andy Panda -, o universo da turma de Walter Lantz era de anti-heróis, onde a competição estava em quem passava melhor a perna no outro e, no fim, os dois lados acabavam perdendo mais do que ganhando.

Outra coisa que Lantz invejava em Disney era a sua retratação de seres humanos. Na Branca de Neve, por exemplo, todas as personagens humanas (e as animais também) tinham movimentos reais. Isso era obtido ao filmar atores reais e depois rotoscopiar (em uma explicação enxuta, desenhar gravuras por cima de cada frame) as imagens.

Além disso, os humanos de Disney eram o ideal da beleza. Príncipes, princesas e, até mesmo, a bruxa má tinham a boa aparência enquanto traço distintivo. Walter Lantz achou também que seus curtas de animação tinham que retratar humanos. No entanto, para isso, ele achou válido misturar os animais antropomorfizados com personagens humanas, algo só feito com certa frequência nos desenhos animados da Betty Boop pré-Código Hays (o namorado de Betty, nos primeiros curtas, era um cachorro antropomorfizado, mas a insinuação de bestialismo era inaceitável para a autocensura).

Os humanos de Lantz eram o oposto daqueles de Disney. Feios, pouco realistas, narigudos, seu traço parecia antecipar, em linhas gerais, algo que seria colocado em prática nos anos 1950 pela UPA e pelas agências publicitárias de televisão. No entanto, o importante aqui não é apenas o traço, mas os grupos sociais retratados.

Nada de realeza ou personagens medievais distantes dos Estados Unidos imerso nos anos 1940. Walter Lantz desenhou imigrantes italianos e irlandeses, cowboys, bandidos, a mulher urbana de meia idade, negros e índios norte-americanos.

Todos esses seres humanos - párias para a sociedade norteamericana tradicional, que é definida pela sigla WASP [White anglosaxan protestant], ou seja, o branco de origem anglo-saxã e protestante 
RAFAEL DUARTE OLIVEIRA VENANCIO - Protagonismo dos índios norte-americanos...

- entravam no jogo anti-heroico, colocados de igual a igual com os animais antropomorfizados, especialmente com Woody Woodpecker.

Uma coisa é interessante de afirmar: a presença dos índios norteamericanos. Com o Código Hays, atitudes embebidas de preconceito racial eram proibidas de serem retratadas nos filmes e desenhos animados. No entanto, enquanto o negro começava a ser retratado com diferentes tramas, o índio foi sendo esquecido pela indústria cinematográfica.

Entre 1940 e 1950, Walter Lantz foi um dos realizadores que mais utilizaram índios em suas produções. E, muito mais do que isso, ao tratá-los em pé de igualdade e protagonismo diante dos demais personagens da diegese, garantiu um respeito inédito ao grupo social diante do público norte-americano.

Sioux animado: os índios norte-americanos e Lantz

De acordo com The Walter Lantz Cartune Encyclopedia (2010) e o catálogo do Walter Lantz Animation Archive na UCLA (1998), há registros de dezessete desenhos animados de Lantz retratando índios entre 1929 e 1972. Desses, apenas dois curtas são anteriores ao Woody Woodpecker e não fazem parte da chamada "Turma do Pica-Pau", sendo que todos os outros foram agrupados e reeditados sob essa alcunha para exibição na televisão a partir dos anos 1950-60.

Esses quinze desenhos animados representam quase dez por cento dos desenhos animados de Woody Woodpecker que apresentavam índios enquanto protagonistas das histórias, número bastante alto para a época. É difícil estimar um número exato de desenhos animados realizados por Lantz em toda sua carreira, graças às perdas de filmes mais antigos; no entanto, podemos estimar que os dezessete desenhos animados ocupem um espaço entre três e cinco por cento de toda a sua produção.

Os dezessete desenhos animados que temos registro são: Beau and Arrows (1932), Nellie the Indian Chief's Daughter (1938), Syncopated Sioux (1940), Boogie Woogie Sioux (1942), The Barber of Seville (1944), Slingshot 6 7/8 (1951), Scalp Treatment (1952), Chief 
RAFAEL DUARTE OLIVEIRA VENANCIO - Protagonismo dos índios norte-americanos...

Charlie Horse (1956), International Woodpecker (1957), Heap Bog Hepcat (1960), Papoose on the Loose (1961), Sioux Me (1965), Horse Play (1967), Fat in the Saddle (1968), Buster's Last Stand (1970), Charlie the Rainmaker (1971) e Indian Corn (1972).

Em Beau and Arrows (1932), o primeiro desenho animado de Lantz com índios norte-americanos, não os encontramos enquanto figuras humanas animadas. Sendo um desenho animado de Oswald the Lucky Rabbit, os nativos são retratados enquanto fuinhas antropormofizadas, bastante condizentes com a estética em preto-ebranco do filme.

Retomando as histórias western clássicas, os índios sequestram a namorada de Oswald e a colocam presa em um poste para o "ritual indígena básico" (ficar dançando em volta do tronco em uma dança sincronizada). No entanto, aqui há a diferença. Com sua malandragem, típica dos protagonistas de desenhos animados da golden age, Oswald convence o chefe indígena a soltar sua namorada e, em uma atitude conciliatória incomum para as diegeses western da época, dão um beijo nos dois lados da face do nativo. É interessante que esse chefe, ao contrário dos seus comandados, parece menos fuinha e mais humano, já mostrando os traços que Walter Lantz adotaria para caracterizar os nativos norte-americanos.

Esses traços seriam aprimorados em Nellie the Indian Chief's Daughter (1938). Nellie é uma interessante iniciativa, sendo uma das tentativas de criar uma personagem feminina que pudesse concorrer com Betty Boop, muito modificada e descaracterizada por causa do Código Hays.

No curta, Nellie, apesar de ser uma garota indígena, possui os mesmos hábitos que as garotas urbanas: escuta música, tem fotos de seus ídolos (todos índios) em sua cabana-quarto e tem uma legião de fãs tentando conseguir um encontro com ela. Tal como o chefe indígena de Beau and Arrows, esses pretendentes já possuem traços indicativos: faces com maçãs do rosto proeminentes e bochechas levemente caídas. Além disso, o desenho animado é recheado de gags e não segregam o índio, mas o integra - traduzindo até com certo respeito as diferenças culturais - nos desejos sociais do pré-Segunda Guerra Mundial.

Mas, voltando para o traço, ficou claro que Lantz e seus 
animadores elegeram um povo nativo norte-americano determinado: os Sioux, tal como seria revelado nos dois próximos desenhos animados, já coloridos, Syncopated Sioux (1940) e Boogie Woogie Sioux (1942).

Narizes retos e grandes, bochechas caídas e rosto queimado e incisivo. Todos os índios de Lantz eram variações de Touro Sentado (Thathánka lyotake) e seus guerreiros da parte ocidental dos Sioux, os Lakota. Nos dezesseis desenhos animados da Turma do Pica-Pau, que incluem Syncopated Sioux e Boogie Woogie Sioux, só os Sioux seriam utilizados na representação nativa de Lantz. No entanto, as consequências, evocações e implicações disso serão analisadas na próxima seção.

Continuando na diegese dos desenhos animados, Syncopated Sioux possui claramente os nativos norte-americanos enquanto protagonistas - nem Woody Woodpecker nem Andy Panda aparecem nesse episódio -, e utiliza uma série de gags que, tal como no desenho anterior de Nellie, não segrega os nativos do mundo urbano, mas também não os força a adaptação à civilização.

Esse movimento, que podemos considerar respeitoso - mesmo que tratado em tons cômicos, até por se tratar de um desenho animado -, quando levado em conta a comparação com outras histórias western de seu período, é bem representado em Boogie Woogie Sioux, quando há a união entre índio e jazz.

Apesar de não ser a música dos nativos - fato utilizado enquanto fator cômico na diegese do desenho animado - o jazz estava, de certa forma, posto enquanto pária social no mundo dos desenhos animados. Com o Código Hays em sua cola e querendo ampliar a fama de bom mocismo, os estúdios Disney favoreciam brutalmente a música clássica, considerada mais instrutiva para as crianças e longe do clima de pecado e boemia que o jazz passava nos anos 1930.

Só que não havia nenhuma regra escrita no código de autocensura da indústria cinematográfica que proibia o uso do jazz. Walter Lantz, por sua vez, era um grande entusiasta do gênero musical. Em um acordo com o dono da Universal, Carl Laemmle, e o músico e líder de uma jazzband, Paul Whiteman, Lantz fez a abertura em desenho animado do filme sobre Whiteman, King of Jazz (1930), estrelando Bing Cosby, e, em troca, realizou o curta de Oswald the Lucky Rabbit, My Pal 
Paul (1930), uma espécie de teaser do filme estrelando o famoso coelho de desenho animado.

Além disso, Lantz realizou alguns desenhos animados avulsos que apresentavam caricaturas de músicos famosos do campo. Imitando o Gato Félix em Felix in Hollywood (1923), Oswald the Lucky Rabbit inspirado em Douglas Fairbanks quando estava nas mãos de Disney e Iwerks - revelou sua nova inspiração em Al Jolson, a estrela do primeiro talkie, The Jazz Singer (1927), no curta Hot for Hollywood (1930).

Lantz levava tão sério a sincronização do som com a imagem do desenho animado que não relutava em copiar o método Disney de usar o metrônomo para coincidir tempo musical com tempo de animação. Fotos do estúdio Lantz comprovam que os diretores e animadores tinham metrônomos em suas mesas quando iam transpor do storyboard as cenas dos curtas.

The Barber of Seville (1944) é o desenho animado de Lantz que mostra com plenitude o domínio desse método. Nela, Woody Woodpecker assume uma barbearia e atende vários clientes ao som do trecho mais famoso da ópera homônima de Gioachino Rossini. Leonard Maltin (1987) descreve bem a produção desse desenho animado,

The Barber of Seville é um excelente desenho animado no qual Woody toma conta da barbearia de Tony e coloca um par de clientes insuspeitos na navalha. $O$ segundo, um trabalhador da construção civil, pede pelo "serviço completo" e Woody começa, entrando no clima para barbear e cortar o cabelo ao cantar o "Largo el Factotum" do Barbeiro de Sevilha. Sua performance vigorosa dessa conhecida ária dá o ritmo para as gags. As ações de Woody se tornam mais rápidas e furiosas quando a música acelera; é uma perfeita mistura de som e imagem. Quando tenta achar seu cliente, que fugiu em pânico, Woody se divide em três, depois quatro, e então cinco figuras de si mesmo enquanto ele grita por Figaro na famosa sequência, na qual os cortes aparecem no ritmo de cinco ou seis frames cada (um quarto de segundo!). O desejo do [diretor do curta, recém-contratado pelo estúdio, James] Culhane de desenhar pantomima através da personagem não foi abandonado. Woody é uma personagem rica e visualmente expressiva nesse desenho animado. Suas expressões faciais, bem como suas ações, estão lindamente sincronizadas com a música (MALTIN, 
1987, p. 170).

Nesse desenho animado musical, o primeiro cliente de Woody é um índio, claramente baseado no Touro Sentado, denominado Chief. $\mathrm{O}$ ponto aqui é que ele não é tratado enquanto civilizado - aliás, podemos até dizer que Lantz era contra a civilização dos índios pelos moldes WASPs, tal como pregava Washington, já que em Heap Big Hepcat (1960), a temática principal do desenho é mostrar as dificuldades de reintegração (quase uma perda de espírito) de um índio "que fez sucesso na cidade grande" -, e pode andar e aparecer em uma barbearia em trajes típicos sem causar um ruído no tecido social urbano (tal como aconteceu com Injun Joe pela pena de Mark Twain).

O desenho animado seguinte de nossa lista, Slingshot $67 / 8$ (1951), é um desenho animado western de Woody Woodpecker. Em 1950, por causa de uma crise nos estúdios Universal, que o estava deixando em um período quase sabático desde 1947, Walter Lantz não produziu nenhum desenho animado.

No entanto, em 1951, Lantz, com o seu novo estúdio autônomo e tendo chegado a bons termos com a Universal, relança o Woody Woodpecker com Puny Express, uma típica paródia dos westerns que tratavam dos mensageiros a cavalo. O filme fez tanto sucesso que, nos anos 1950, Woody quase se tornou um cowboy de tanto aparecer trajado dessa maneira.

Foi nesse surto que Slingshot $67 / 8$ surgiu, mas aqui os índios norte-americanos não são seres humanos animados. Aqui, o índio é Buzz Buzzard, um antagonista de Woody, mas não o vilão da história. O urubu funcionava para o pica-pau tal como, no Looney Tunes, o coiote funciona para a ave papa-léguas, ou seja, não há mocinhos e vilões aqui.

A mesma coisa com Scalp Treatment (1952), onde o índio Buzz Buzzard luta pelo amor de uma índia norte-americana (essa é humana e muito parecida com Nellie) com Woody. No final, nenhum consegue uma vitória cem por cento, já que Woody teve que ficar sem nenhuma pena para dar um longo cocar para a moça.

Interessante notar aqui que esse desenho animado possui o mesmo nome de uma gag que aparece nos desenhos animados de Lantz 
RAFAEL DUARTE OLIVEIRA VENANCIO - Protagonismo dos índios norte-americanos...

sobre os nativos norte-americanos. Scalp Treatment é uma clara referência ao costume indígena de tirar os escalpos de seus inimigos. Como discutiremos na próxima seção, Lantz dá aqui um tom diferente daquele adotado por Twain e outros nesta questão.

Em Chief Charlie Horse (1956), novamente, Woody não se encontra nos melhores dos cenários quando resolve trabalhar enquanto comerciante de artefatos "indígenas" criados por ele. Ele acaba se envolvendo com um xerife trapalhão e um indígena bandido, cujo crime foi Scalping Rose Bowl Tickets (uma piada entre tirar o escalpo de Rose com roubar ingressos para algum jogo no Rose Bowl), outra referência à clássica gag.

No entanto, mesmo nesse raro caso de caracterização de um indígena enquanto criminoso, Woody coloca sua própria ordem e, enganando os dois - especialmente o xerife -, consegue retornar ao cotidiano (índio solto e o xerife prendendo a estátua de madeira), mas dez mil dólares mais rico.

Em International Woodpecker (1957), Woody conta a história do mundo e, quando chega à conquista do Oeste americano, faz uma das melhores críticas, utilizando como base Stagecoach, a esse movimento da história norte-americana. Compelido ao Go West, Woody volta cheio de flechas para a Costa Leste e recebe o recado: "Melhor ir de trem na próxima vez". Nada de heroísmos baratos ou histórias de superação diante da "ameaça" indígena.

Esse desenho animado possui outra característica digna de nota. Talvez pela primeira vez nos desenhos animados clássicos, a namorada do protagonista - Mickey tinha Minnie, Oswald a sua coelhinha e Woody tem a Winnie Woodpecker - leva a melhor no final do desenho animado, dando uma surra em Woody por causa do mau tratamento histórico dos homens diante das mulheres (representado no início do desenho animado pelo "flerte" entre pica-paus da caverna).

No anteriormente referido, Heap Bog Hepcat (1960), vemos uma crítica feroz e cômica contra o índio civilizado nos padrões WASP. Desvinculado de sua cultura por causa das máquinas e da riqueza do "homem branco", o índio chorão deixa de ser pretendente da bela índia (e perde seu carro) para Woody.

Papoose on the Loose (1961) é um bonito desenho animado sobre 
RAFAEL DUARTE OLIVEIRA VENANCIO - Protagonismo dos índios norte-americanos...

a relação pai-filho em uma aldeia aldeia nativa americana. Bem ao estilo dos desenhos animados que surgiram nos anos 1950 com a UPA, utilizando gags familiares, a iniciação dos indiozinhos à vida adulta é retratada dentro de bons parâmetros culturais (não há referência à cultura WASP), e nem por isso deixa de trabalhar o universal "pai se dá mal para o filho se dar bem", um paradigma do desenho animado.

Sioux Me (1965) é mais um representante de um ano recheado de westerns na Turma do Pica-Pau, talvez influenciado pelo revival do gênero com os Spaghetti Westerns. Aqui, Woody e Fink Fox são uma dupla de malandros que tenta se dar bem em cima de um chefe Sioux. Tal como o verbo e a prerrogativa dos desenhos de Lantz já nos fazem deduzir, só tentam se dar bem, sobrando um scalp treatment para Fink.

Em Horse Play (1967), vemos Woody e seu cavalo Sugarfoot tentando se passar por membros de tribo indígena para tentar salvar o escalpo e a vida do cavalo. Por não gostar de Sugarfoot, o índio é punido comicamente, sendo a única vez que um nativo "se dá mal" sozinho nos desenhos animados de Walter Lantz.

Fat in the Saddle (1968) é uma espécie de remake de Puny Express (1951). Só que, sem a temática dos bandidos, Woody Woodpecker e Sugarfoot encontram um índio que gosta de colecionar selos e, em um acidente de "trânsito", acaba se encontrando com a dupla de mensageiros. No fim, o índio se torna uma espécie de "coiote" da dupla "papa-léguas", que culmina em um fim sem vencedores.

O nome de Buster's Last Stand (1970) é uma clara referência aos Sioux e à vitória deles na Batalha de Little Bighorn. No entanto, o desenho animado conta a história de um índio que tenta criar um cocar com o topete de Woody Woodpecker para ganhar o concurso e casar com a filha do chefe.

Novamente, aqui há o retorno da fórmula "coiote-papa-léguas". No fim, os dois viram amigos e Woody ajuda o índio a criar um cocar "maluco" (com esquilos e rodas gigantes). No fim, o índio apaixonado casa com a filha do chefe que é, na verdade, uma feiosa, e o chefe indígena adota o Pica-Pau como grande amigo.

Charlie the Rainmaker (1971) é uma paródia de Boogie Woogie Sioux, mas aqui é o urso Beary que tenta aprender a dança indígena da chuva, totalmente caracterizado enquanto um nativo norte-americano. 
A gag do fracasso é a grande temática aqui.

Por fim, Indian Corn (1972) é o último desenho com a temática nativa norte-americana, produzido no último ano de Walter Lantz na animação. Há aqui o abandono da tática "coiote-papa-léguas" e o retorno às gags sobre scalp treatment com Woody, Buzz, e o pai e filho de Papoose on the Loose. No entanto, em uma virada indicando mudança de tempos, o pequeno índio é o único prejudicado na história, por não ter seguido as determinações da cultura indígena.

Tendo descrito todos esses desenhos animados, podemos partir para análise do protagonismo dos índios norte-americanos no trabalho fílmico de Walter Lantz. Para isso, temos que ir além da diegese indicada e ver os vínculos sociais através do arcabouço teórico composto pelos conceitos de dispositivo e fórmula.

\section{Agindo no Mundo da Vida: fórmula e dispositivo}

A noção de dispositivo foi cunhada por Jean-Louis Baudry (1975) em Le dispositif: approches métapsychologiques de l'impression de réalité. Em suma, o dispositivo é a visão do cinema enquanto

um sistema constituído de três níveis articulados: 1) a tecnologia de produção e exibição (câmera-projetortela); 2) o efeito psíquico de projeção-identificação e o ilusionismo; 3) o complexo da Indústria Cultural como instituição social produtora de um certo imaginário (BAUDRY apud AUMONT, 2004, p. 46).

Muito mais do que dar continuidade ao debate Adorno-Benjamin, em seu terceiro ponto, o dispositivo por Baudry dialoga com outros conceitos irmãos que compartilham o mesmo nome. Na maioria deles, especialmente naqueles compartilhados por pós-estruturalistas e pósmodernos, o dispositivo implica dois fatores cruciais para sua operação: uma questão de poder (controle, sedução, legitimação) e uma questão de linguagem (discurso, escritura).

Mas como isso se relaciona à fórmula do desenho animado, o mecanismo linguístico próprio de cada realização do campo? Ora, antes de partir para a resposta dessa questão central, seria interessante 
RAFAEL DUARTE OLIVEIRA VENANCIO - Protagonismo dos índios norte-americanos...

esmiuçar, usando um processo de inter-relação teórica, os três pontos do dispositivo.

O primeiro deles são as questões de concretização da prática midiática audiovisual: câmera-projetor-tela. Aqui, o que está em jogo são questões da Arte e da Estética, o do como fazer e de que forma apresentar.

Já o segundo, o efeito psíquico de projeção-identificação e o ilusionismo, já significa as questões de interação e recepção com o público. São questões da Cultura, do privado, do interpessoal, da constituição individual e social da psique.

Por fim, o terceiro ponto, da Indústria Cultural, está nas questões que chamamos sistêmicas. É a relação do produto audiovisual não só com a Economia, com a Política do seu tempo, mas também com as ideologias.

Interessante notar que o segundo e o terceiro ponto se relacionam com a constituição dual das formas de agir no mundo - suas racionalidades, seus movimentos de Aufklarung -, para Jürgen Habermas (2001). É o jogo entre a ação comunicativa (par do segundo ponto) e ação instrumental (par do terceiro ponto).

Essa racionalidade dupla, onde uma legitima/modifica a outra, parte da distinção habermasiana, dos conceitos hegelianos do período de lena, entre trabalho (racionalidade/ação instrumental) e interação (racionalidade/ação comunicativa).

A ação instrumental é a racionalidade regida por regras técnicas apoiadas no saber empírico. Isso implica numa teleologia, ou seja, em previsões sobre o mundo que implicam na escolha de estratégias. São essas estratégias analíticas que montam toda a gramática social na qual vivemos. A Política, o Estado, a Economia, as ideologias do mundo estão neste campo, pois elas possibilitam a reprodução material da sociedade. À parcela do mundo regida pela ação instrumental, Habermas (2001) dá o nome de Sistema.

Já a ação comunicativa está calcada na interação simbolicamente mediada, em poucas palavras, no cotidiano social. É o campo da tradição, da cultura, da fofoca, da família e do socialmente compartilhado. A validade de qualquer coisa neste campo depende do acordo mútuo proporcionado pela intersubjetividade, envolvendo 
intenções e reconhecimento geral das obrigações.

Com isso, a ação comunicativa é "orientada para o entendimento e não para a manipulação de objetos e pessoas no mundo em vista da reprodução material da vida (como é o caso da racionalidade instrumental)" (NOBRE, 2004, p. 56). É o espaço do chamado Mundo da Vida, do vívido cotidiano.

As duas racionalidades - a ação instrumental e a ação comunicativa -, em interação, vão desenhando a realidade das relações sociais contemporâneas. No entanto, há algo cuja racionalidade normalmente foge do Sistema e do Mundo da Vida. Isso, para os críticos de Habermas, é o campo da Arte e suas regras próprias. Essa racionalidade artística é o ponto-chave do primeiro ponto do dispositivo, utilizando uma lógica bem próxima daquela atribuída à palavra estética desde a Escola de Wolf e consolidada por Hegel.

Com isso, ao destrinchar o conceito de dispositivo, ampliando-o, nos deparamos com o seguinte quadro, dividindo o dispositivo em longos três ramos onde cada ponto-chave de sua definição se relaciona com uma racionalidade e seu campo de ação:

Quadro 1: O conceito de dispositivo e seus campos de ação.

\begin{tabular}{|l|c|c|c|}
\cline { 2 - 4 } \multicolumn{1}{c|}{} & Pontos-chaves & Racionalidade & Campo de Ação \\
\hline \multirow{3}{*}{ Dispositivo } & Câmera-projetor-tela & Arte/Estética & Outras obras de arte \\
\cline { 2 - 4 } & Interação psíquica & Mundo da Vida & Cultura e Cotidiano \\
\cline { 2 - 4 } & Indústria Cultural & Sistema & Política e Economia \\
\hline
\end{tabular}

Fonte: Elaboração do autor a partir de Baudry (1975) e Habermas (2001).

Dessa forma, o conceito de dispositivo mimetiza a própria sociedade em si, mostrando a relação intrínseca entre as três racionalidades. Tal como as três partes de um nó borromeano, Sistema, Mundo da Vida e Estética, estão inter-relacionadas e cada um desses elos sustenta os demais. Sem um deles não há nada, não há mais o nó, não há mais a sociedade. 
RAFAEL DUARTE OLIVEIRA VENANCIO - Protagonismo dos índios norte-americanos...

Assim, qualquer desenho animado acaba priorizando um desses três campos para tentar se fixar enquanto prática midiática relevante no todo social. Ora, sabemos que ele se fixa através do mecanismo linguístico que denominamos fórmula (syuzhet) do desenho animado. Syuzhet define, normalmente, aquilo que chamamos de trama ( $p / o t)$, ou seja, o arranjo narrativo, o movimento sintagmático da apresentação e da história a ser contada. Isso faz Bordwell (1997, p. 50) chamá-la de arquitetônica da narrativa.

No entanto, a tradução "trama" para syuzhet reduz muito a capacidade metalinguística do termo. O syuzhet não é apenas uma trama qualquer, ou mesmo uma trama única de um dado filme ou produto audiovisual. Ele, principalmente se pensarmos em produções seriadas ou em práticas com amplo campo intertextual (ambas presentes no desenho animado), ganha o status de receita.

Tal como uma receita de bolo, o syuzhet precisa de uma ordem definida de componentes que, em si, podem ser trocados por outros similares. É como em uma receita de bolo. Não podemos colocar o fermento depois que a massa foi ao forno, mas podemos trocar o chocolate por laranja para mudar seu sabor.

É através dessa receita, a fórmula, que o desenho animado age no dispositivo, priorizando um campo de ação, uma racionalidade. Tendo isso em vista, é necessário voltar nossos olhos para o objeto de estudo em questão do presente trabalho, a presença dos nativos norteamericanos em Walter Lantz.

Uma característica aqui é decisiva: a utilização quase total do Lakota Sioux, representados por variações dos traços fisionômicos de Touro Sentado e de seus guerreiros. A escolha aqui é socialmente positiva, porque a tribo, além de não ser inventada ou extinta, possui a fama de brava graças à dura derrota que impôs à Cavalaria norteamericana, comandada pelo General Custer, em Little Bighorn.

Caracterizando-os positivamente, os índios nativos norteamericanos ganham um voto de confiança de Walter Lantz, tal como seus todos personagens. Assim, todos eles podem entrar na grande fórmula do criador de Woody Woodpecker: a demonstração de um outro cotidiano.

A fórmula aqui é simples: se Disney cansa em esbanjar bom 
RAFAEL DUARTE OLIVEIRA VENANCIO - Protagonismo dos índios norte-americanos...

mocismo, Lantz tenta ser o negativo permitido pelas regras da época. Assim, há uma construção de anti-heróis com defeitos que os tornam mais humanos (ou mais próximos dos desejos humanos) do que os personagens Disney (exceto em alguns filmes Disney que acabaram escapando do controle de qualidade do realismo, tal como The Three Caballeros, de 1944, realizado longe dos olhos de Walt).

Assim, os nativos norte-americanos são integrados em um mundo muito mais potencialmente próximo do nosso, e sem precisar ser um civilizado, tal como indicava Washington. Apesar de Woody ser o protagonista, suas derrotas também eram celebradas com o riso da plateia.

Com isso, algumas piadas de mau gosto funcionam dessimbolizando marcos de terror na sociedade norte-americana. Um exemplo disso é o scalp, o ato indígena de tirar o escalpo. Tanto em Cooper como em Twain isso era tratado como uma violência extrema, um ato que colocava em dúvida a própria natureza do índio que o praticava. Já nos desenhos da Turma do Pica-Pau, a gag tirava todo o poder de horror ao vinculá-lo ao próprio topete de Woody, um traço característico e uma gag constante.

Lantz fez isso com a anuência do próprio Código Hays, que nunca o importunou sobre isso. Mesmo com o início da veiculação dos curtas de cinema na televisão, em 1950-60, Lantz sofreu alguns cortes, especialmente nas cenas de alcoolismo (que só seriam retomadas nos anos 1980) ou que indicavam alguma conduta psicotrópica, mas nada que afetasse a scalp treatment gag.

Com o passar dos anos, o que era pioneiro em Walter Lantz, ou seja, essa inserção em um universo diegético equânime se mostrou enquanto tendência no Mundo da Vida, deixando de ser uma marca própria do realizador para ser aceito enquanto temática comum. Os índios podiam ser protagonistas e imersos sem precisar serem civilizados ou tratados enquanto vilões por causa de sua natureza.

Assim, enquanto pioneiro, Lantz pode ser considerado enquanto um construtor de um legado midiático dos nativos norte-americanos. Alguém que deu visibilidade normal a esses povos quando muitos tinham receio de fazê-lo. 
RAFAEL DUARTE OLIVEIRA VENANCIO - Protagonismo dos índios norte-americanos...

Contemporâneos e o legado: índios norte-americanos e seu
protagonismo

Muito do legado de Walter Lantz foi construído, tal como é típico da cultura proporcionada pelos meios de comunicação desde os tempos da reprodutibilidade técnica, juntamente com a exibição de seus desenhos animados. Enquanto o western tradicional, mesmo com a revitalização proporcionada por John Ford e seu Stagecoach, ainda caminhava relutantemente acerca da questão indígena, duas outras realizações audiovisuais tomavam a mesma decisão de Lantz.

O primeiro exemplo disso é The Lone Ranger. Inicialmente, uma novela radiofônica de 1933, logo foi transformada em um serial (série de curtas cinematográficos) produzida pela Republic, em 1938. Apesar da história ser sobre um Texas Ranger misterioso e justiceiro, a história traz Tonto, considerado o primeiro protagonista índio digno de nome.

No entanto, isso possui algumas observações. Tonto representado por um shakespeariano no rádio, mas por um índio no serial (Chief Thundercloud) - não tinha o papel definido como um sidekick, companheiro do herói, até porque, tal como dizia o nome, o herói era um lone ranger, solitário.

Tonto estava mais para o mordomo do Batman, Alfred, que era de grande ajuda para manter a identidade secreta de Bruce Wayne, sendo apenas um sidekick ocasional (denominado aide). Seria com o spinoff da série sobre o sobrinho do Lone Ranger, The Green Hornet, que acharíamos a figura do sidekick-mordomo com Kato (imortalizado na TV por Bruce Lee).

Na série de TV, em 1949-57, com o ator mohawk Jay Siverheels, que Tonto recebeu um melhor destaque. Só que a falta de critério em definir Tonto enquanto um legítimo sidekick estereotipou a personagem tal como um "Pai Tomás" indígena, deixando a série e Siverheels no ostracismo. Tonto tinha o erro de ser civilizado demais, contrariando a caracterização já posta em prática por Walter Lantz.

No entanto, é indiscutível o ganho social que Tonto proporcionou à representação midiática dos índios norte-americanos. Era uma das poucas realizações live action que arriscava colocar um indígena em tal 
posição de destaque na diegese.

Mas seria apenas com o nosso segundo exemplo, o revival do western pelo Spaghetti Western, nos anos 1960, que os índios realmente poderiam seguir, no mundo do live action, à moda dos desenhos animados de Walter Lantz, e fugir seja da maldade natural dos livros do fim do século XIX, seja da subserviência de Tonto. No entanto, o Spaghetti Western tinha uma peculiaridade diegética.

Umberto Eco, ao analisar as diferenças entre a trama clássica Édipo Rei e o enredo espetacular moderno Stagecoach, afirma que no filme de John Ford tudo ocorre no nível do enredo. Assim, "não há nenhuma tentativa de análise psicológica, cada caráter já vem definido do modo mais convencional possível, e cada gesto é milimetricamente previsível" (ECO, 1991, p. 22).

Tal como o romance popular, o filme vem para abrandar as expectativas do público, tornando-se "antes de tudo 'popular' porque [é] 'demagógico'” (ECO, 1991, p. 23). No entanto, a fórmula de Stagecoach é levada ao extremo na produção europeia do gênero conhecida como Spaghetti Western.

Esse subgênero é caracterizado como uma forma de simplificação do enredo do western tradicional. Essa afirmação tem como metáfora o diálogo de John Ford com Burt Kennedy, onde o último resume a fórmula do Spaghetti Western como "sem história, sem cenas. Só matança" (KENNEDY apud FRAYLING, 2006, p. 35).

Esses filmes não eram apenas sucesso de bilheteria, mas adoçavam a cena alternativa-revolucionária que desencadearia em 1968. Entre as perguntas da época, citadas por Frayling (2006), duas são as melhores caracterizadoras do fenômeno do Spaghetti Western:

Podia o cinema popular (distinto do trabalho artístico de Godard, Godard e Godard) ser realmente político? (...) Porque o "momento" dos Italian Westerns agradou tanto as crianças de Marx e Coca-Cola na Europa, especialmente a geração de Maio de 1968? (FRAYLING, 2006, p. XV).

Aqueles filmes mal-feitos, distantes de Hollywood, começaram a ser o maior destaque não só em suas terras natais, mas em toda cena norte-americana, mesmo fora de Berkeley. Eles eram uma alternativa, 
um grito de basta ao western tradicional, que pregava o ode ao bom moço e o preconceito contra grupos marginalizados. No Spaghetti Western, o herói era o anti-herói (ou mesmo o inimigo) para o mainstream do WASP norte-americano: o bandido, o caçador de recompensas, o mexicano, o mercenário, o outsider e o nativo norteamericano.

Assim, algo que era um alternativo comercial lançado fora do grande centro de produção ganhou status de revolucionário. Assim, tal como Woody Woodpecker, o Spaghetti Western se caracterizava por um universo de anti-heróis onde os índios norte-americanos poderiam existir como uma representação fílmica equânime com os outros grupos étnicos e sociais.

Os desejos humanos eram mais bem vistos nessas produções do que seus rivais na Disney e nos seguidores de John Wayne e John Ford. E, por um critério histórico - não só por anterioridade, mas também porque Woody Woodpecker e o lado surreal (e escondido) de Donald faziam amplo sucesso fora dos Estados Unidos, especialmente na América Latina e Itália -, podemos até falar que Walter Lantz antecipa muito o que elogiaríamos nas telonas com Sergio Leone, Sergio Corbucci, entre outros.

É claro que o surgimento de filmes tais como Dances With Wolves (1990), The Last of the Mohicans (1992) e Geronimo (1993) pode ser considerado como a grande ascensão nativa norte-americana ao cinema - tal como o longa Disney Pocahontas (1995) para o desenho animado -, e estes são grandes exemplos enquanto representação positiva.

No entanto, não podemos esquecer a alta romantização da figura indígena nesses filmes citados. Implica, no limite, em uma relação social da figura midiática do indígena enquanto pertencente a um mundo de fantasia, normalmente considerado o objetivo de Hollywood e grande lema de Walt Disney.

Só que, com Walter Lantz e os Spaghetti Westerns, os índios possuem uma ponderação melhor na sua entrada no Mundo da Vida. E aqui é interessante colocar: é melhor, para a representação desses povos nativos norte-americanos, a fórmula romântica no Mundo da Vida (que, por sua vez, implica em uma fórmula sistêmica de não agressão ao mainstream do politicamente correto) ou a ampla inserção na fórmula 
RAFAEL DUARTE OLIVEIRA VENANCIO - Protagonismo dos índios norte-americanos...

anti-heróica no Mundo da Vida, onde os índios são dignos de nossa atenção tais como quaisquer personagens, com todas suas peculiaridades culturais (mesmo que tratadas ao limite)?

Se à pergunta acima não cabe resposta, podemos, no entanto, seguir um pequeno raciocínio. Raciocínio esse que segue pelo caminho da pluralidade. Ora, em um mundo romântico, a bipolaridade do bemmal sempre será evidente. Os tons de cinza são sempre os anti-heróis da paleta de cores.

\section{Referências bibliográficas}

AUMONT, Jacques. O olho interminável. São Paulo: Cosac \& Naify, 2004.

BAUDRY, Jean-Louis. Le dispositif: approches métapsychologiques de l'impression de réalité. Communications, Paris, n. 23, p. 56-72, 1975.

Cinema: Efeitos ideológicos produzidos pelo aparelho de base. In: XAVIER, Ismail (Org.). A experiência do cinema. Rio de Janeiro: Graal, 1983. p. 381-399.

BORDWELL, David. Narration in the Fiction Film. London: Routledge, 1997.

COOPER, James F. The Last of Mohicans. New York: Bantam, 1982.

ECO, Umberto. O Super-homem de Massa. São Paulo: Perspectiva, 1991.

FRAYLING, Christopher. Spaghetti Westerns: Cowboys and Europeans from Karl May to Sergio Leone. London/New York: I.B./Taurus, 2006.

HABERMAS, Jurgen. Técnica e ciência como “ideologia”. Lisboa: Ed. 70, 2001.

MALTIN, Leonard. Of Mice and Magic. New York: Plume, 1987.

MILLER, Eric L. Caunotaucarius: George Washington and Indians. 1994. Disponível em: http://www.dreric.org/library/contents.shtml . Acesso em: 16 jun. 2011.

NOBRE, Marcos. A teoria crítica. Rio de Janeiro: Jorge Zahar Editor, 2004.

RISSETTO, Adriana. Romancing the Indian: Sentimentalizing and Demonizing in Cooper and Twain. In: RAILTON, Stephan. Mark Twain in His Times. Virginia: University of Virginia, $1996 . \quad$ Disponível em: http://etext.lib.virginia.edu/railton/projects/rissetto/main.html . Acesso em: 16 jun. 2011. 
RAFAEL DUARTE OLIVEIRA VENANCIO - Protagonismo dos índios norte-americanos...

THE WALTER LANTZ-O-PEDIA. The Walter Lantz Cartune Encyclopedia. 2010. Disponível em: http://lantz.goldenagecartoons.com. Acesso em: 16 jun. 2011.

TWAIN, Mark. The Noble Red Man. In: RAILTON, Stephan. Mark Twain in His Times. Virginia: University of Virginia, 1996. Disponível em: http://etext.virginia.edu/railton/projects/rissetto/redman.html . Acesso em: 29 jun. 2011. TWAIN, Mark. The Adventures of Tom Sawyer. New York: Tribeca, 2011.

UNIVERSITY OF CALIFORNIA. Find Aid for the Walter Lantz Animation Archive, 1940-1979. Catálogo de Arquivo. Los Angeles: UCLA, 1998. 